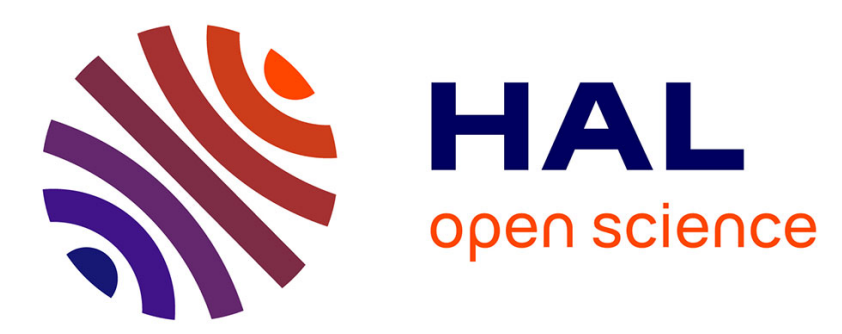

\title{
Riverine-driven interhemispheric transport of carbon
}

Olivier Aumont, J.C. Orr, P. Monfray, Wolfgang Ludwig, P. Amiotte-Suchet, J.L. Probst

\section{To cite this version:}

Olivier Aumont, J.C. Orr, P. Monfray, Wolfgang Ludwig, P. Amiotte-Suchet, et al.. Riverinedriven interhemispheric transport of carbon. Global Biogeochemical Cycles, 2001, 15 (2), pp.393-405. 10.1029/1999GB001238 . hal-02677020

\section{HAL Id: hal-02677020 \\ https://hal.inrae.fr/hal-02677020}

Submitted on 17 Sep 2021

HAL is a multi-disciplinary open access archive for the deposit and dissemination of scientific research documents, whether they are published or not. The documents may come from teaching and research institutions in France or abroad, or from public or private research centers.
L'archive ouverte pluridisciplinaire HAL, est destinée au dépôt et à la diffusion de documents scientifiques de niveau recherche, publiés ou non, émanant des établissements d'enseignement et de recherche français ou étrangers, des laboratoires publics ou privés. 


\title{
Riverine-driven interhemispheric transport of carbon
}

\author{
Olivier Aumont, ${ }^{1,2}$ James C. Orr, ${ }^{1}$ Patrick Monfray, ${ }^{1}$ Wolfgang Ludwig, ${ }^{3}$ Philippe \\ Amiotte-Suchet, ${ }^{4}$ and Jean-Luc Probst, ${ }^{5}$
}

\begin{abstract}
Controversy surrounds the role of the ocean in interhemispheric transport of carbon. On one hand, observations in the atmosphere and in the ocean both seem to imply that the preindustrial ocean transported up to $1 \mathrm{Pg} \mathrm{C} \mathrm{yr}^{-1}$ from the Northern to the Southern Hemisphere. On the other hand, three dimensional (3-D) ocean models suggest that global interhemispheric transport of carbon is near zero. However, in this debate, there has been a general neglect of the river carbon loop. The river carbon loop includes (1) uptake of atmospheric carbon due to inorganic and organic erosion on land, (2) transport of carbon by rivers, (3) subsequent transport of riverine carbon by the ocean, and (4) loss of riverine carbon back to the atmosphere by air-sea gas exchange. Although carbon fluxes from rivers are small compared to natural fluxes, they have the potential to contribute substantially to the net air-sea fluxes of $\mathrm{CO}_{2}$. For insight into this dilemma, we coupled carbon fluxes from a global model of continental erosion to a 3-D global carbon-cycle model of the ocean. With rivers, total southward interhemispheric transport by the ocean increases from 0.1 to $0.35 \pm 0.08 \mathrm{Pg} \mathrm{Cyr}^{-1}$, in agreement with oceanographic observations. Resulting air-sea fluxes of riverine carbon and uptake of $\mathrm{CO}_{2}$ by land erosion were installed as boundary conditions in a 3-D atmospheric model. The assymetry in these fluxes drives a preindustrial atmospheric gradient of $\mathrm{CO}_{2}$ at the surface of $-0.6 \pm 0.1 \mu \mathrm{atm}$ for the North Pole minus the South Pole and longitudinal variations that exceed $0.5 \mu \mathrm{atm}$. Conversely, the gradient for Mauna Loa minus South Pole is only $-0.2 \pm 0.1 \mu \mathrm{atm}$, much less than the $-0.8 \mu \mathrm{atm}$ gradient extrapolated linearly from historical atmospheric $\mathrm{CO}_{2}$ measurements from the same two sites. The difference may be explained by the role of the terrestrial biosphere. Regardless, the river loop produces large gradients both meridionally and zonally. Accounting for the river carbon loop changes current estimates of the regional distribution of sources and sinks of $\mathrm{CO}_{2}$, particularly concerning partitioning between natural and anthropogenic processes.
\end{abstract}

\section{Introduction}

Sarmiento and Sundquist [1992] showed that before industrialization, the ocean lost naturally $\sim 0.6 \mathrm{Pg} \mathrm{Cyr}^{-1}$ of riverine carbon to the atmosphere. This natural oceanic efflux must be added to the total air-sea $\mathrm{CO}_{2}$ flux estimates in order to derive the anthropogenic component, as predicted directly by ocean models. Regionally, sea-to-air fluxes of

\footnotetext{
'Laboratoire des Sciences du Climat et de l'Environnement, Gifsur-Yvette, France.

${ }^{2}$ Now at Laboratoire d'Oceanographie Dynamique et de Climatologie, Paris, France.

${ }^{3}$ Centre de Formation et de Recherche sur l'Environnement Marin, Université de Perpignan, Perpignan, France.

${ }^{4}$ Laboratoire GéoSol, Dijon, France.

${ }^{5}$ Laboratoire des Mécanismes de Transferts en Géologie, Toulouse, France.

Copyright 2001 by the American Geophysical Union.

Paper number 1999GB001238.

0886-6236/01/1999GB001238\$12.00
}

riverine carbon must also be important, but this has never been quantified.

Many atmospheric modeling studies suggest that the present north-south gradient of atmospheric $\mathrm{CO}_{2}$, a major constraint for the carbon budget, implies a larger sink in the Northern than in the Southern Hemisphere (the so-called "missing sink") [Keeling et al., 1989; Tans et al., 1990; Ciais et al., 1995; Law et al., 1996]. Inverse modeling techniques have since reconstructed the regional distribution of the sources and sinks of carbon from the observed variations of atmospheric $\mathrm{CO}_{2}$, to infer the location of this sink [Fan et al., 1998; Rayner et al., 1999; Bousquet et al., 1999]. Unfortunately, these studies give very different results. In particular, the existence, nature, and location of a large Northern Hemisphere sink remain a matter of debate. Differences in atmospheric $\mathrm{CO}_{2}$ between hemispheres are caused by two factors: (1) asymmetries in sources and sinks, either of anthropogenic or natural origin and (2) the rectifier effect, defined as the seasonal covariance between atmospheric transport and $\mathrm{CO}_{2}$ fluxes between the terrestrial biosphere and the atmosphere during preindustrial time [Pearman and Hyson, 
1980, Heimann et al., 1986, Keelıng et al , 1989, Denning et al., 1995].

A linear extrapolation of historical atmospheric $\mathrm{CO}_{2}$ observations collected since the late 1950 s suggests that preindustrial $\mathrm{CO}_{2}$ concentrations at South Pole were on average about $0.8 \pm 0.2 \mu \mathrm{atm}$ higher than those at Mauna Loa $\left(18^{\circ} \mathrm{N}\right)$ [Keeling et al., 1989; Taylor and Orr, 2000]. That extrapolated atmospheric gradient motivated Keeling et al. [1989] to propose a large southward interhemispheric transport of carbon by the ocean during preindustrial time, which acted to create a sink in the Northern Hemisphere balanced by a source in the Southern Hemisphere [Keeling et al., 1989; Siegenthaler and Sarmiento, 1993]. This hypothesis is supported by subsequent observational studies [Broecker and Peng, 1992; Keeling and Peng, 1995; Stephens et al., 1999] that estimate a significant southward transport of carbon in the ocean, between 0.3 and $0.6 \mathrm{Pg} \mathrm{Cyr}^{-1}$. These studies are based on measurements made in the Atlantic Ocean and on the hypothesis that all of the transport is due to the Atlantic thermohaline circulation. Yet these estimates generally do not take into account the freshwater mass transport which may play a significant role as pointed out by $\mathrm{Hol}$ fort et al. [1998]. Simulations with 3-D ocean models predict southward interhemispheric transport in the Atlantic of roughly the same magnitude, but that is essentially balanced by northward transport in the Pacific and Indian Oceans. Thus, when integrated globally, cross-equatorial transport is negligible $\left(<0.1 \mathrm{Pg} \mathrm{Cyr}^{-1}\right)$ [Sarmiento et al., 2000; Orr, 1999]. However, these global ocean model estimates have not accounted for the contribution of riverine carbon.

The river carbon loop provides the land route by which carbon is transferred from the atmosphere to the ocean. This loop begins with the continental uptake of atmospheric $\mathrm{CO}_{2}$ by (1) weathering of silicate and carbonate rocks and (2) the net biological production on land that is lost to rivers by erosion of organic carbon in soils (Figure 1). Thus, owIng to this organic and inorganic continental erosion, rivers transport carbon from land to ocean, mainly in the Northern Hemisphere. Almost half of river carbon discharge occurs in the Arctic and the North Atlantic, north of the equator. Some of that discharge is incorporated into the deep ocean and is transported southward by the thermohaline circulatoon. Evaluation of the regional impact of transport of riverIne carbon within the ocean upon air-sea fluxes of $\mathrm{CO}_{2}$ has been hindered by the lack of regionalized estimates of the river discharge of carbon.

In this paper, we exploit recent estimates of the preindustrial river discharge provided by a model of continental erosion [Amiotte-Suchet and Probst, 1995; Ludwig et al., 1996b; Ludwig and Probst, 1998]. We have used those fluxes as additional boundary conditions to a 3-D global ocean carbon-cycle model [Aumont, 1998; Aumont et al., 1999] as a means to evaluate the contribution of rivers to preindustrial ocean carbon fluxes. We further use resulting arr-sea fluxes of $\mathrm{CO}_{2}$ as boundary conditions to a 3-D atmo-

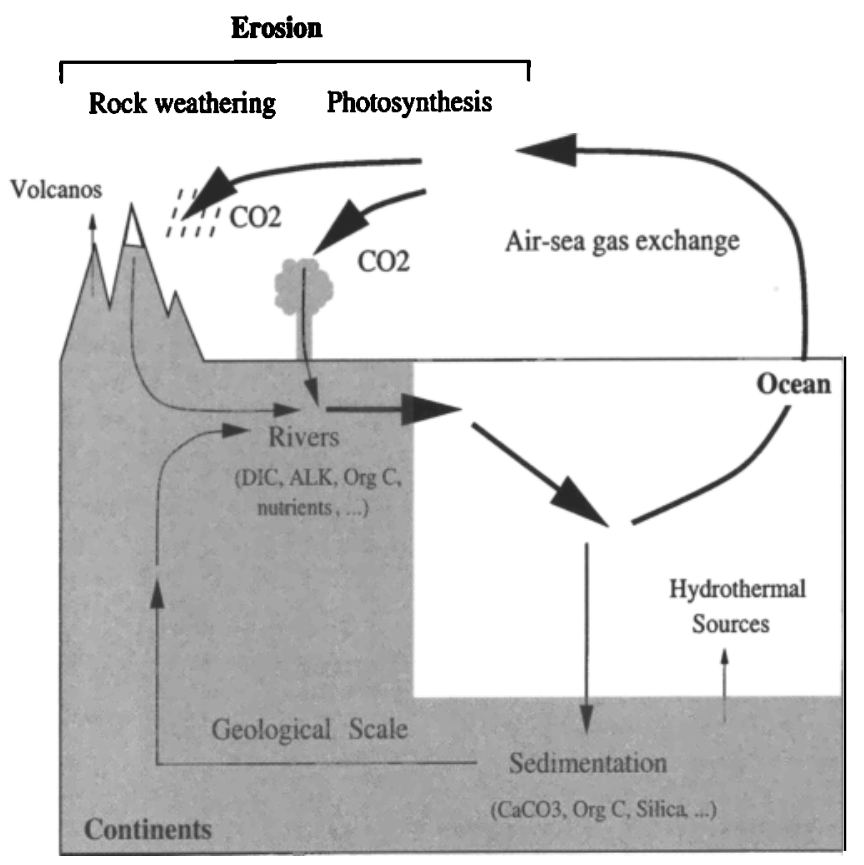

Figure 1. Schematic of the river carbon loop

spheric tracer transport model [Heimann and Keeling, 1989; Heimann, 1995] to estimate the contribution of the river carbon loop to preindustrial gradient in atmospheric $\mathrm{CO}_{2}$.

\section{Models}

This study is based on the use of three different models. (1) a global erosion model which computes total contunental erosion on the continents (i.e., rock weathering and erosion of soils) and resulting river discharge to the oceans, (2) a 3-D global ocean carbon-cycle model, and (3) a 3-D atmospheric transport model.

The Global Erosion Model (GEM) is based on empirical relations existing between observed river fluxes and the biological, climatological, and geomorphological characterıstics of river basins. The river carbon fluxes are first computed in their source regions on the continents using global data sets for the corresponding controlling factors; carbon is then transported to the oceans following a global river routine scheme [Miller et al., 1994; Ludwig et al., 1996a] GEM separates the contribution of inorganic and organic carbon The former is entirely dissolved (dissolved inorganic carbon, DIC) whereas the latter is divided into dissolved (dissolved organic carbon, DOC) and particulate (particulate organic carbon, POC) forms. Contributions from underground rivers are neglected. GEM predicts a total carbon transfer from land to sea of $0.81 \mathrm{PgC} \mathrm{yr}^{-1}$, of which $0.70 \mathrm{Pg} \mathrm{Cyr}^{-1}$ originates from the atmosphere [Ludwig and Probst, 1998] The difference, $0.11 \mathrm{Pg} \mathrm{Cyr}^{-1}$, comes from dissolution of carbonate rocks. Most of the total $\mathrm{C}$ discharge (85\%) is located in the Northern Hemisphere, of which $56 \%$ is released in 
a)

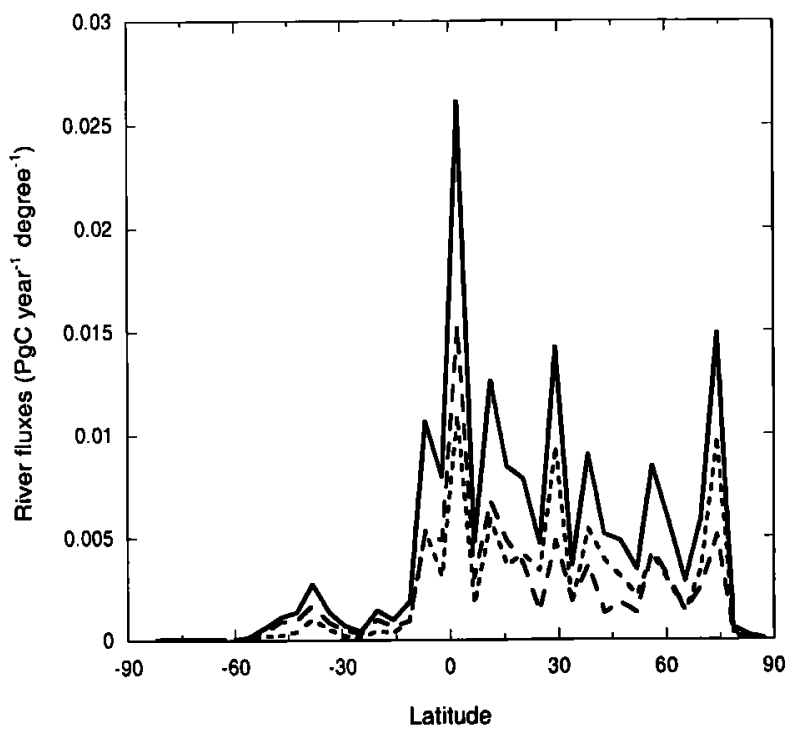

c)

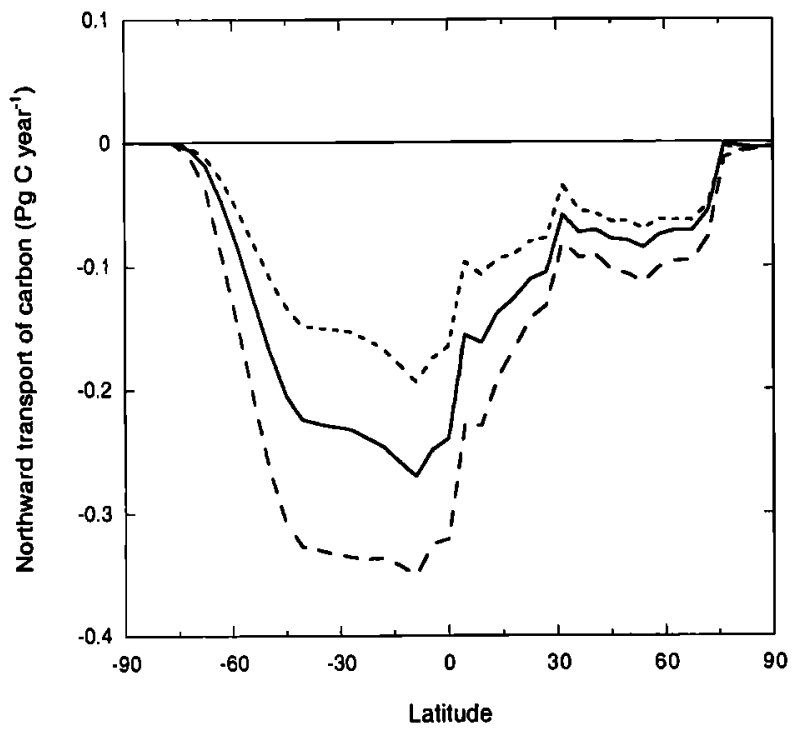

b)

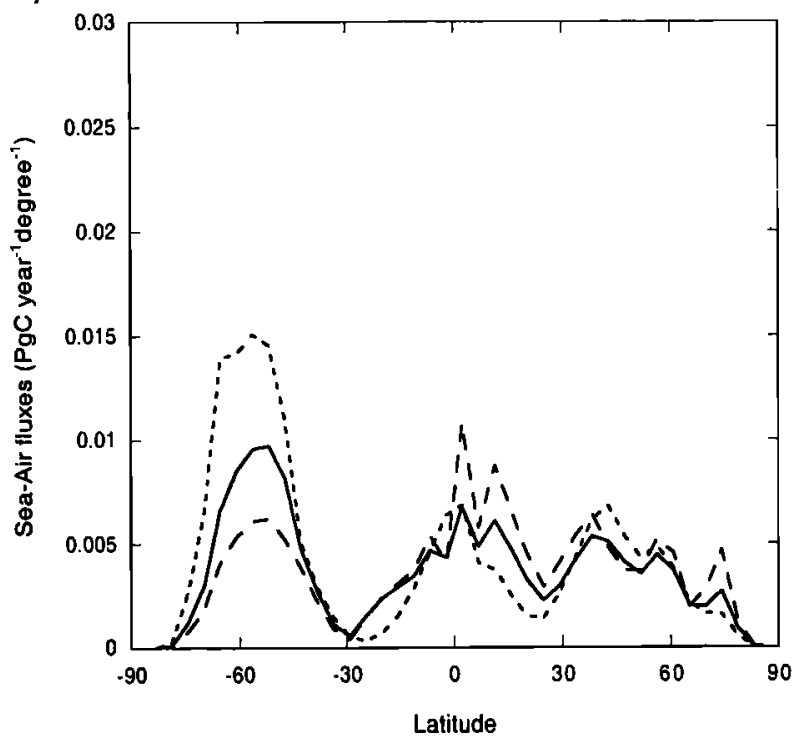

d)

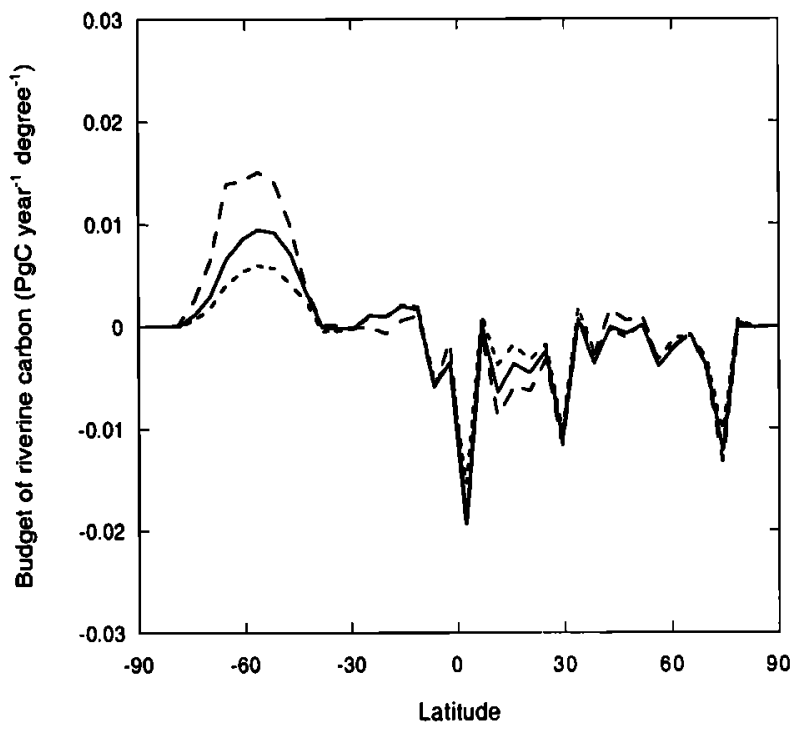

Figure 2. Zonal integrals of (a) the river input of organic carbon, both in particulate and dissolved forms (long dashes), of inorganic carbon (dashes), and of their sum, total carbon (solid); (b) the change in annual mean sea-air fluxes of $\mathrm{CO}_{2}$ due to the river discharge of carbon for the standard simulation (solid), the labile experiment (long dashes), and the refractory experiments (dashes). (c) Annual global change in the northward transport of carbon within the ocean due to the river discharge of carbon for the standard simulation (solid), for the labile experiment (long dashes), and for the refractory experiment (dashes). Negative numbers correspond to a southward transport. (d) Net gain in riverine carbon within the ocean for the standard simulation (solid), for the labile experiment (long dashes), and for the refractory experiment (dashes). These curves correspond to the sea-air fluxes of riverine carbon minus the river input of river carbon (Figure $2 b$ minus Figure 2a).

the Arctic and North Atlantic Oceans (north of the equator) (Figure 2a). Peak inputs occur just north of the equator and in the high latitudes. Globally, delivery of riverine carbon is split nearly equally between organic $\left(0.4 \mathrm{Pg} \mathrm{Cyr}^{-1}\right)$ and inorganic $\left(0.41 \mathrm{Pg} \mathrm{C} \mathrm{yr}^{-1}\right.$ ) forms; however, regional differences between those components are substantial, with relatively higher organic to inorganic carbon ratios in the tropics.
We used the same ocean carbon-cycle model as Aumont [1998] and Aumont et al. [1999], which couples the general circulation model OPA (Océan Parallelisé) [Delecluse et al., 1993; Madec and Imbard, 1996] to the biogeochemical model HAMOCC3 (Hambourg model of the ocean carboncycle, version 3) [Maier-Reimer, 1993] (IPSL model). The horizontal resolution of OPA is on average $2^{\circ}$ by $1.5^{\circ}$ with 
a higher resolution at the equator $\left(0.5^{\circ}\right)$. The model has 30 vertical layers among which 10 are located in the top hundred meters. This model is forced by monthly mean climatologies of wind stress [Hellermann and Rosenstein, 1983] and heat and water fluxes [Oberhüber, 1988]. OPA is run in a semidiagnostic mode, that is, modeled temperatures and salinities are damped toward climatological values throughout most of the water column. There is no damping near the equator, along coasts, in the high latitudes, and in the mixed layer. A feature of OPA is that it predicts vertical eddy diffusivity and viscosity coefficients throughout the water column from equations of the turbulent kinetic energy (TKE) model [Gaspar et al., 1990; Blanke and Delecluse, 1993]. Other global circulation models typically prescribe these coefficients; unlike the TKE model, they do not capture observed extremes and sharp gradients of these coefficients. Processes governing the ocean carbon cycle are simulated by the biogeochemical model HAMOCC3 [Maier-Reimer, 1993]. This model computes the fluxes resulting from the biological activity rather than describing this biological activity itself. Export production is assumed proportional to the local phosphate concentration but is modulated by light, temperature, mixed layer depth, and abundance of nutrients. Organic matter and calcareous tests sink instantaneously below the euphotic zone (set uniformly to $50 \mathrm{~m}$ ) according to prescribed vertical profiles.

In rivers, inorganic carbon is transported as bicarbonate. Thus alkalinity is also delivered to the oceans by rivers, with the same magnitude as DIC, that is $0.033 \mathrm{Peq} \mathrm{yr}^{-1}$. This input of alkalinity is exactly balanced in the ocean model by the sedimentation of inorganic carbon, which we assume is proportional to the calcite flux at the base of the water column. We neglected sedimentation of riverine particulate organic matter since most organic matter present in marine sediments is of oceanic origin [Jorgensen, 1983; Hedges and Keil, 1995]. We also neglected riverine input of nutrients, for which regional estimates are not available.

Balancing river input of alkalinity requires that 0.2 of the $0.81 \mathrm{Pg} \mathrm{Cyr}^{-1}$ delivered by rivers is buried in the sediments as calcite. Thus globally, the amount of river carbon that returns to the atmosphere is $0.61 \mathrm{Pg} \mathrm{Cyr}^{-1}$. The imbalance between this outflux from the ocean and the continental uptake of atmospheric $\mathrm{CO}_{2}\left(0.7 \mathrm{Pg} \mathrm{C} \mathrm{yr}^{-1}\right)$ is 0.09 $\mathrm{Pg} \mathrm{C} \mathrm{yr}{ }^{-1}$ according to GEM. This imbalance is balanced by a supply of $\mathrm{CO}_{2}$ from volcanos and hydrothermal activity [Berner, 1990]. The partitioning of this source between the hydrothermal and the volcanic sources is uncertain [Des Marais, 1985; Arthur et al., 1985]. To estimate the maximum impact on southward transport of carbon in the ocean, we assumed that all of this supply is hydrothermal in origin. We added this carbon to our ocean model by injecting it at the ocean floor. In our model, these fluxes were weighted according to the local area between 1500 and 3500 $\mathrm{m}$, where most ocean ridges are located. The resulting interhemispheric transport was near zero $\left(\leq 0.03 \mathrm{Pg} \mathrm{C} \mathrm{yr}^{-1}\right)$. It is further neglected.
The reactivity of riverine organic carbon is uncertain. Smith and Hollibaugh [1993] estimate that about one third of the land-derived organic matter is remineralized rapidly within the estuaries and the coastal zones. Such oxidation partly explains the remarkably elevated $\mathrm{pCO}_{2}$ values observed in those areas, especially in the inner estuaries [Frankignoulle et al., 1998]. The remaining $2 / 3$ is refractory with typical lifetimes of several decades [Meybeck, 1993b]. In this work, we did not distinguish organic matter between particulate and dissolved forms. In our standard simulation, we released $1 / 3$ of the riverine organic carbon in the model as DIC at the river mouths. The model transports the remaining $2 / 3$ as DOC which is oxidized with a timescale of 100 years. The ocean carbon-cycle model including the riverine carbon input was run for 5000 years, until the model drift was at quasi-equilibrium (i.e., until the modeled sea-air flux was only $0.02{\mathrm{PgC} \mathrm{yr}^{-1}}^{-1}$ less than the equilibrium value of $0.61 \mathrm{PgC} \mathrm{yr}^{-1}$ ).

The regional distribution of the natural sources and sinks of $\mathrm{CO}_{2}$ acts to create regional variations of atmospheric $\mathrm{CO}_{2}$. To test the impact on the interhemispheric and intrahemispheric distribution of these fluxes on atmospheric $\mathrm{CO}_{2}$, we used the fluxes predicted by the ocean model and by GEM to drive the 3-D atmospheric tracer-transport model TM2 developed at the Max-Planck Institut für Meteorologie in Hamburg [Heimann and Keeling, 1989; Heimann, 1995]. Our version of TM2 was modified from its original $10^{\circ} \times 8^{\circ}$ resolution to $7.5^{\circ} \times 7.5^{\circ}$ by Ramonet [1994]. The vertical resolution of TM2 is nine isosigma layers. This model is run for 4 years, repeating the reanalyzed wind fields for 1990 from the European Centre for Medium-Range Weather Forecasting (ECMWF). For our analysis we use annual mean results from the fourth year of the simulation.

\section{Results}

\subsection{Interhemispheric Oceanic Transport of Carbon}

Figure $2 b$ shows the zonally integrated distribution of the air-sea fluxes of riverine carbon as predicted by the coupled GEM-IPSL model. The fluxes are dominated by the maximum outgassing in the Southern Ocean. About 1/3 of the global loss of riverine carbon occurs south of the polar front. In this region, rivers are few indeed. Thus part of the riverine carbon released in the Northern Hemisphere penetrates into the intermediate and deep ocean. This deep natural sequestration is especially efficient in the North Atlantic ocean where deep convection and formation of the North Atlantic Deep Water occur. Large amounts of riverine carbon are delivered directly, as well as indirectly to this region: most of the carbon which is supplied by rivers in the Arctic Ocean is trapped below the ice sheet and is further advected into the North Atlantic Ocean. For example, much of the Arctic riverine carbon is transported through the Fram Strait into the Greenland Sea, an important region of deep-water formation. After deep sequestration and transport southward 
(in deep waters), much of this carbon is brought back to the surface in the Southern Ocean by the Antarctic divergence and by deep convective mixing (Figure $2 \mathrm{c}$ ).

Besides the Southern Ocean, two other oceanic regions lose substantial riverine carbon: the high latitudes of the Northern Hemisphere and the tropics. Such outgassing results from (1) the large supply of riverine carbon and (2) the efficient connection between the surface and the deeper waters. Thus part of the riverine carbon lost to the deep ocean is returned to the surface. However, unlike the Southern Ocean, the supply of riverine carbon exceeds, in these regions, its rate of loss from the surface ocean to the atmosphere. Consequently, both the northern high latitudes and the equatorial regions still supply riverine carbon to the rest of the ocean, and in particular to the Southern Ocean (Figure $2 \mathrm{~d}$ ). Our model estimates that net export of riverine carbon to the deep ocean is $0.1 \mathrm{PgC} \mathrm{yr}^{-1}$ in the northern high latitudes (north of $60^{\circ} \mathrm{N}$ ) and $0.19 \mathrm{PgC} \mathrm{yr}^{-1}$ in the tropics (between $15^{\circ} \mathrm{S}$ and $15^{\circ} \mathrm{N}$ ).

Estimating the fate of the riverine carbon that is supplied to the rest of the ocean from the equatorial regions and the northern high latitudes is rather difficult. This would require many additional simulations, each of which is extremely computer intensive, to precisely determine the regions where carbon is lost back to the atmosphere. Nevertheless, the amount of riverine carbon which is transported out of both regions $\left(0.29 \mathrm{PgC} \mathrm{yr}^{-1}\right)$ is close to that lost from the Southern Ocean in excess of the riverine carbon supplied there $\left(0.25 \mathrm{Pg} \mathrm{C} \mathrm{yr}^{-1}\right)$. In the northern high latitudes, riverine carbon is sequestered in the deep ocean mostly in the North Atlantic ocean and transported southward by the North Atlantic Deep Water. In the equatorial regions, part of the riverine carbon is transported by the subtropical gyres southward to the Southern Ocean; another part is transported northward to the northern high latitudes where some of it is subsequently subducted into the deep ocean. A relatively long lifetime for riverine organic matter improves the efficiency of this transport, as demonstrated in subsequent sensitivity experiments.

To explore uncertainties associated with the reactivity of the riverine organic carbon, we ran two sensitivity tests, which we would consider extreme scenarios: in our labile scenario, all land-derived organic matter was released in the model as DIC at the river mouths; in our refractory scenario, riverine organic matter was assumed to have a lifetime of 4000 years. In the latter case, riverine organic matter is effectively homogenized throughout the entire ocean before being remineralized. Both experiments differ from the standard simulation mainly by the amount of riverine carbon that is lost from the Southern Ocean (Figure 2b). Loss of riverine carbon from the Southern Ocean increases as the landderived organic matter becomes more refractory, i.e., as less of this organic matter is oxidized at the surface and more is oxidized within the intermediate and deep ocean. In the refractory scenario, half of the river carbon is lost back to the atmosphere south of the Polar Front. In the labile scenario, outgassing in the Southern Ocean is reduced. Thus, in the labile scenario, most of the riverine carbon escapes back to the atmosphere in the Northern Hemisphere, not far from where it first encounters the ocean. The short equilibration time for $\mathrm{CO}_{2}$ between the atmosphere and surface ocean (1 year Broecker and Peng [1974]) then plays a greater role in limiting penetration of river carbon into the intermediate and deep ocean, which is a prerequisite for long distance transport.

Our three experiments all predict that rivers produce a net cross-equatorial transport of carbon from the Northern to the Southern Hemisphere (Figure 2c). The magnitude of southward transport is $0.25 \mathrm{Pg} \mathrm{Cyr}^{-1}$ in the standard simulation, $0.17 \mathrm{Pg} \mathrm{C} \mathrm{yr}^{-1}$ in the labile scenario, and $0.33 \mathrm{Pg} \mathrm{Cyr}^{-1}$ in the refractory scenario (Table 1). After adding the $0.1 \mathrm{Pg}$ $\mathrm{C} \mathrm{yr}^{-1}$ southward transport predicted by our ocean model simulation without riverine carbon, our total preindustrial interhemispheric transport is $0.35 \pm 0.08 \mathrm{Pg} \mathrm{C} \mathrm{yr}^{-1}$. Our estimate is similar to the $0.3-0.6 \mathrm{Pg} \mathrm{Cyr}^{-1}$ interhemispheric transport estimated from atmospheric [Stephens et al., 1999] or oceanographic [Broecker and Peng, 1992; Keeling and Peng, 1995] data. In summary, including oceanic transport of riverine carbon in model simulations appears to resolve controversy between observed versus modeled estimates of preindustrial interhemispheric carbon transport.

\subsection{Atmospheric $\mathrm{CO}_{2}$}

By transporting carbon from the northern extreme of the Northern Hemisphere to the southern extreme of the South-

Table 1. Preindustrial Northward Transport of Carbon Within the Ocean and Resulting Gradient of Atmospheric $\mathrm{CO}_{2}$ Between South Pole and North Pole and South Pole (SPO) and Mauna Loa (MLO) ${ }^{a}$

\begin{tabular}{lccc}
\hline & $\begin{array}{c}\text { Interhemispheric Transport, } \\
\text { Pg C yr }^{-1}\end{array}$ & $\begin{array}{c}\text { North-South Gradient, } \\
\mu \mathrm{atm}\end{array}$ & $\begin{array}{c}\text { MLO-SPO Gradient, } \\
\mu \mathrm{atm}\end{array}$ \\
\hline Ocean alone & -0.10 & -0.10 & 0.20 \\
Standard simulation & -0.25 & -0.50 & -0.40 \\
Labile scenario & -0.17 & -0.40 & -0.30 \\
Refractory scenario & -0.33 & -0.6 & -0.5 \\
Ocean plus rivers & $-0.35 \pm 0.08$ & $-0.60 \pm 0.10$ & $-0.20 \pm 0.10$ \\
\hline
\end{tabular}

\footnotetext{
aWhen adding river and ocean alone components, the displayed value corresponds to the standard simulation. The deviation results from the labile and refractory scenarios which are considered as extreme cases.
} 


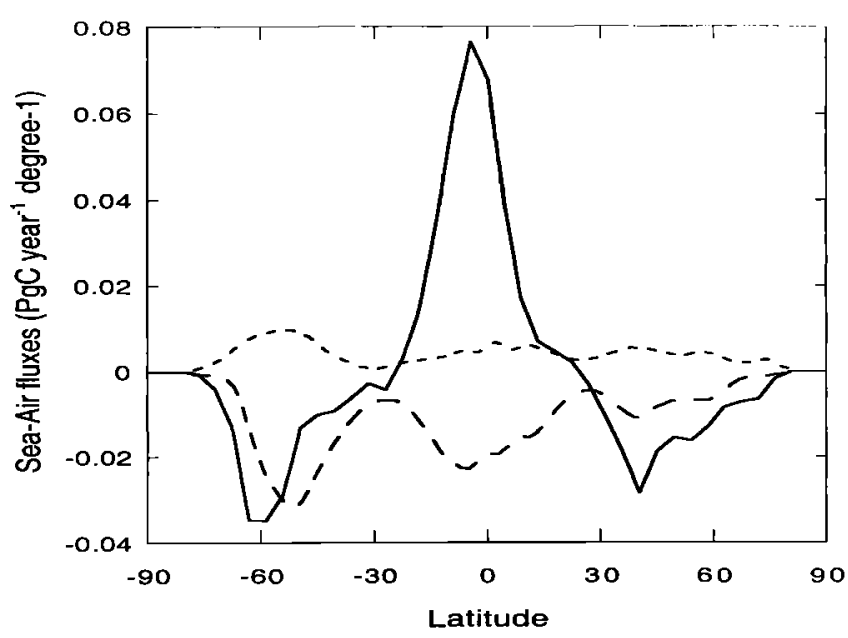

Figure 3. Zonal integrals of annual mean sea-air fluxes of $\mathrm{CO}_{2}$ from the ocean component of the natural carbon cycle (solid), oceanic uptake of anthropogenic $\mathrm{CO}_{2}$ in year 1990 (long dashes), and riverine carbon component in the standard case (dashes).

ern Hemisphere (Figure 3), the river carbon loop creates interhemispheric differences in atmospheric $\mathrm{CO}_{2}$. To evaluate these differences, we used the 3-D atmospheric transport model TM2 with boundary conditions from our air-sea fluxes of riverine plus oceanic carbon (GEM-IPSL) and land uptake due to total erosion (GEM) (Figure 4). The majority of the sink of atmospheric $\mathrm{CO}_{2}$ due to continental erosion (both organic and inorganic) is located in the Northern Hemisphere. The distribution of the continents is biased in the same sense. The GEM model predicts a Northern Hemisphere total sink due to erosion of $0.49 \mathrm{Pg} \mathrm{Cyr}^{-1}$, which represents nearly $70 \%$ of the total erosion sink. Most of the erosive land sink occurs in the northern high latitudes and in the equatorial regions (see Fig. 4a). In the northern high latitudes, large riverine DOC fluxes derive from extensive drainage of organic-rich soils of the tundra and taiga. These regions along with western Europe and eastern North America also absorb large amounts of atmospheric $\mathrm{CO}_{2}$ due to chemical weathering of extensive outcrops of carbonate rocks. The erosive sink of $\mathrm{CO}_{2}$ in the tropics is dominated by southeastern Asia, Indonesia, and the Amazon basin. Intense erosion of organic carbon in those regions is due to their strong drainage intensity under wet and warm climates, and their abundance of shale, which is, after carbonates, the rock type with the second highest specific $\mathrm{CO}_{2}$ consumption by rock weathering [Amiotte-Suchet and Probst, 1995]. Unlike the other equatorial regions, relatively small $\mathrm{CO}_{2}$ consumption is found over Africa. There chemical weathering is limited due to the abundance of plutonic and metamorphic rocks as well as sandstones. Furthermore, African drainage intensity is almost 3 times lower than in South America and still 2 times lower than in Southeast Asia [Ludwig and Probst, 1998].
Figure 4a also shows the regional distribution of the preindustrial air-sea fluxes of $\mathrm{CO}_{2}$ simulated in the standard case. These fluxes result in part from the combination of the solubility and the biological pumps. Figure 4a also includes the contribution of riverine carbon from our standard simulation, which is displayed alone on Figure $4 \mathrm{~b}$. The regional patterns of the preindustrial air-sea fluxes of $\mathrm{CO}_{2}$ are similar to those from other global ocean carbon-cycle models [Sarmiento et al., 2000]. The cooling of warm water masses as they are advected northward produces a strong sink of atmospheric $\mathrm{CO}_{2}$ in the North Atlantic and North Pacific oceans. The strongest ocean source of $\mathrm{CO}_{2}$ for the atmosphere is located in the equatorial Pacific ocean where DICrich waters are brought to the surface and warmed. In the Southern Ocean, the region between $40^{\circ}$ and $60^{\circ} \mathrm{S}$ is largely a source of $\mathrm{CO}_{2}$ for the atmosphere. Despite oceanic uptake due to cooling (solubility pump), deep convection and the Antarctic Circumpolar Current bring to the surface intermediate and deep waters that are enriched in DIC by the biological activity (biological pump). Furthermore the efflux of oceanic carbon is significantly enhanced by degassing of riverine carbon. The magnitude of the air-sea fluxes of riverine carbon in the Southern Ocean and in the North Atlantic Ocean is similar to that of the net natural air-sea fluxes of $\mathrm{CO}_{2}$ (see Figure 3). Thus total $\mathrm{pCO}_{2}$ measurements made in these regions contain a significant fraction due to the river carbon loop.

Without riverine carbon, the simulated North Pole-South Pole gradient of atmospheric $\mathrm{CO}_{2}$ is $-0.1 \mu \mathrm{atm}$ (Figure 5a, Table 1). In this ocean-only case, atmospheric $\mathrm{CO}_{2}$ does vary a great deal with latitude, with large peak of $1 \mu \mathrm{atm}$ at the equator relative to South Pole. This peak is produced by the large equatorial source associated with the sinks in the high latitudes.

The sink of atmospheric $\mathrm{CO}_{2}$ due to continental erosion and the source to the atmosphere from the ocean as supplied by riverine carbon are concentrated at nearly opposite ends of the Earth (Figures 3 and 4). It is this spatial decoupling which drives regional variations in atmospheric $\mathrm{CO}_{2}$. Uptake of carbon on land is mostly located in the Northern Hemisphere. The continental erosion sink lowers atmospheric $\mathrm{CO}_{2}$ concentrations by $0.4 \mu \mathrm{atm}$ at the North Pole relative to the South Pole (Figure $5 b$ ). Without any southward oceanic transport of riverine carbon, sea-air fluxes of riverine carbon would provide a mirror image to the river discharge of carbon. Such is not the case because southward transport of riverine carbon within the ocean creates a large outflux in the Southern Ocean (Figure 4b). Thus resulting sea-air fluxes from our standard simulation cause atmospheric $\mathrm{CO}_{2}$ to be $0.1 \mu \mathrm{atm}$ higher at the South Pole relative to the North Pole. For the labile simulation, that difference is nearly zero; for the refractory simulation, the difference is $0.2 \mu \mathrm{atm}$. Overall the river carbon loop causes $\mathrm{CO}_{2}$ concentrations at the North Pole to be $0.5 \pm 0.1 \mu \mathrm{atm}$ lower than those at the South Pole. 
a)
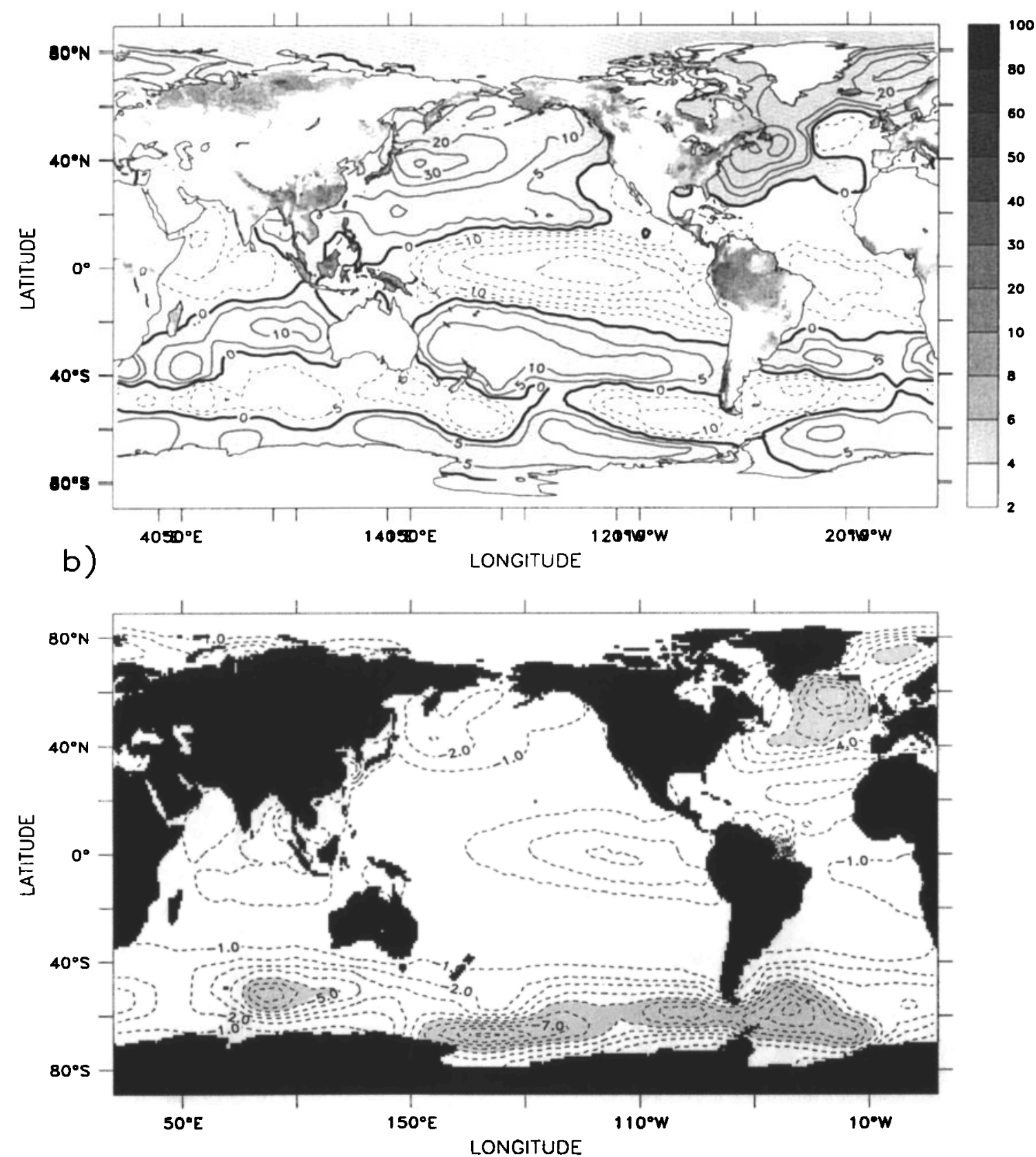

Figure 4. The predicted annual-mean fluxes of $\mathrm{CO}_{2}$ from the atmosphere $\left(\mathrm{mol} \mathrm{C} \mathrm{m}^{-2} \mathrm{yr}^{-1}\right)$ for (a) the coupled GEM-IPSL model with continental erosion and air-sea fluxes of oceanic and riverine carbon (standard case) and (b) air-sea fluxes of riverine carbon only (standard case).

The river carbon loop drives zonal as well as meridional variability in atmospheric $\mathrm{CO}_{2}$. Figure $6 \mathrm{a}$ shows a map of this variability for the standard case, with all grid points shown as their $\mathrm{CO}_{2}$ concentration minus that at South Pole. The maximum difference reaches nearly $0.7 \mu \mathrm{atm}$. Maximum relative concentrations of $0.1 \mu \mathrm{atm}$ are found in the Southern Ocean near the Amundsen and Bellinghausen Seas, where the ocean model simulates the greatest loss of riverine carbon due to deep convection (see Figure 4b). Minimum relative concentrations, about $-0.6 \mu \mathrm{atm}$, are found over the largest land sink of $\mathrm{CO}_{2}$ in Siberia (see Figure 4a). The greatest zonal variability $(0.4 \mu \mathrm{atm})$ is found in the tropics, between the Andes (a strong continental sink due to erosion) and the equatorial Pacific ocean (a source of riverine car- 

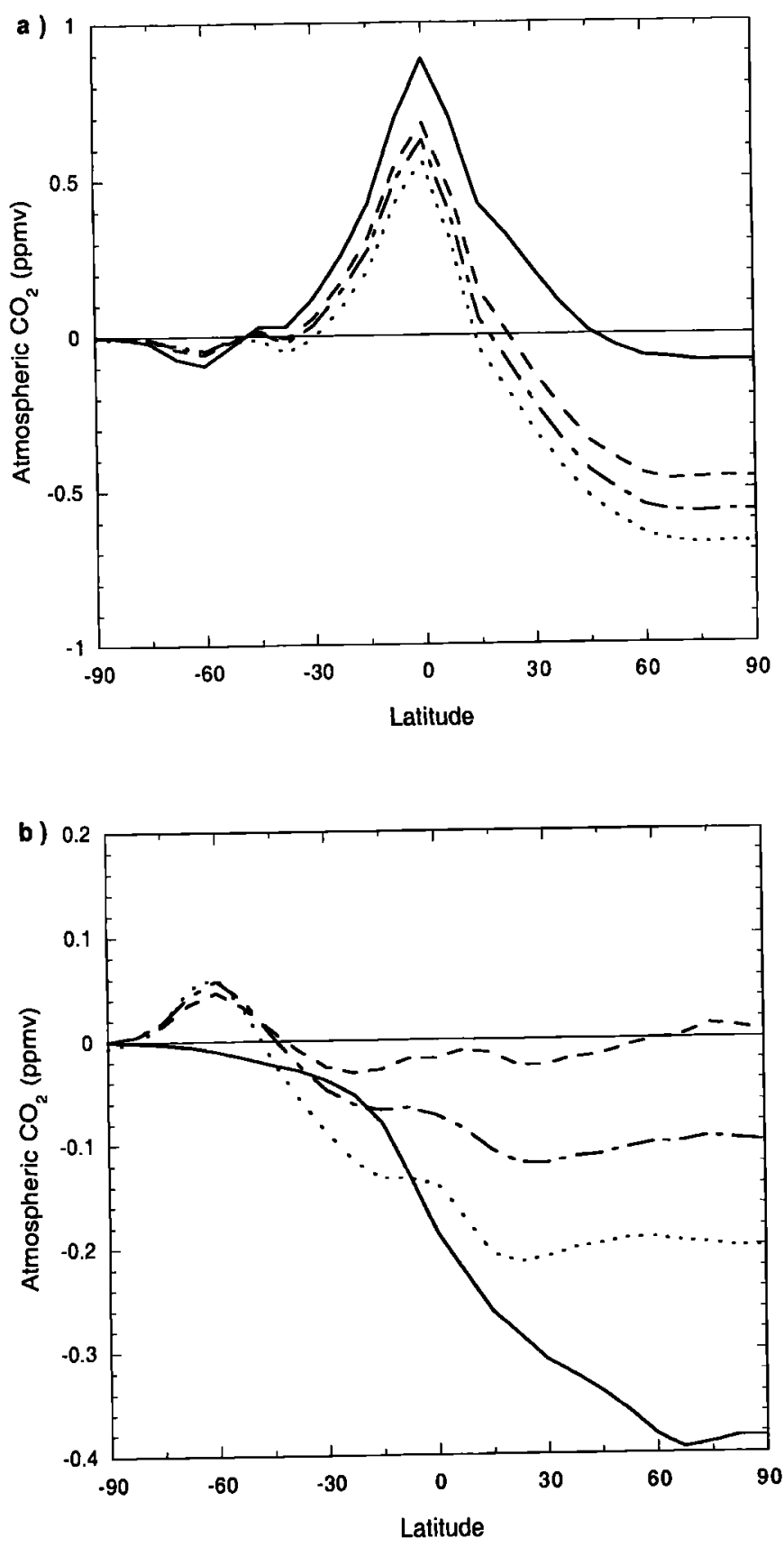

Figure 5. Latitudinal variation of zonally averaged atmospheric $\mathrm{CO}_{2}$ concentrations at the surface as predicted by the atmospheric model: (a) Contribution of the ocean alone (solid) and of the ocean plus rivers for the standard simulation (dash-dots), the labile simulation (dashes), and the refractory simulation (dots); (b) the effect of river carbon loop on atmospheric $\mathrm{CO}_{2}$, separated into components due to continental erosion (solid) and fluxes of riverine carbon across the air-sea interface for the standard simulation (dash-dots), the labile simulation (dashes), and the refractory simulation (dots). The effect of the continental uptake is estimated by using the regional distribution of continental erosion predicted by GEM as boundary conditions to the atmospheric model. Figures 5a and $5 \mathrm{~b}$ display differences between the $\mathrm{CO}_{2}$ concentration at each grid cell minus that at South Pole. bon). This dipole is partially enhanced by the topography of the Andes, which inhibits mixing of the eastward trade winds. In Southeast Asia, the zonal mixing due to trade winds is not limited by topography, and the resulting zonal gradient is only $0.3 \mu \mathrm{atm}$ despite a stronger continental sink.

After adding the riverine carbon loop to the ocean-only component, we predict a preindustrial North Pole-South Pole gradient in atmospheric $\mathrm{CO}_{2}$ of $-0.6 \pm 0.1 \mu \mathrm{atm}$ (Figure $5 \mathrm{a}$, Table 1). Between 70 and $85 \%$ of this gradient is due to the river carbon loop, i.e. uptake of atmospheric carbon on land, transport of riverine carbon from land to sea, subsequent southward oceanic transport of riverine carbon, and loss back to the atmosphere. The remaining $15-30 \%$ is due to the ocean-only component (i.e., sea-air fluxes of oceanic carbon).

Sea-air fluxes of oceanic carbon are nearly symmetric. Thus they do not create substantial assymetry in atmospheric $\mathrm{CO}_{2}$ between Northern and Southern Hemispheres. However, they do enhance regional variation of atmospheric $\mathrm{CO}_{2}$ (Figure 6b). The maximum difference relative to the South Pole is $1.8 \mu \mathrm{atm}$ over the equatorial Pacific ocean where substantial oceanic carbon is lost to the atmosphere near the equatorial divergence. The minimum relative difference, $0.65 \mu \mathrm{atm}$, is found over the North Pacific Ocean due to both the river carbon loop and the ocean's natural tendency to absorb carbon in that region. Thus maximum variability is 2.5 $\mu \mathrm{atm}$. The maximum zonal gradient is again between the equatorial Pacific Ocean and the Andes. However, the intensity of that dipole rises from 0.4 to $1.8 \mu \mathrm{atm}$ when the air-sea fluxes of oceanic carbon are included.

\section{Discussion}

\subsection{Uncertainties}

Our simulated atmospheric $\mathrm{CO}_{2}$ concentrations at MaunaLoa minus South Pole of $-0.2 \pm 0.1 \mu \mathrm{atm}$ (Table 1) is much less than the about $-0.8 \pm 0.2 \mu \mathrm{atm}$ estimated by linear extrapolation from the atmospheric record [Keeling et al., 1989; Taylor and Orr, 2000]. Can this difference be explained by uncertainties or bias in our approach? One uncertainty is that we neglected river input of nutrients. Riverine nutrients are delivered mostly as organic matter at the rate of $0.048 \mathrm{Pg} \mathrm{N} \mathrm{yr}^{-1}$ [Meybeck, 1993a]. They may stimulate primary productivity by at most $0.3 \mathrm{Pg} \mathrm{Cyr}^{-1}$, assuming a $\mathrm{C} / \mathrm{N}$ ratio of 7.6 [Takahashi et al., 1985]. The resulting impact on atmospheric $\mathrm{CO}_{2}$ depends on where nutrients are made available for biological uptake, i.e. on the reactivity of the organic matter. If this organic matter were labile, river nutrients would be released mostly in the Northern Hemisphere, where enhanced primary productivity would tend to decrease concentrations of atmospheric $\mathrm{CO}_{2}$. However, if this organic matter were refractory, a substantial portion of riverine nutrients would be transported southward of the Polar Front. In that region, biological activity is limited neither by phosphate nor by nitrate. Consequently, the effect of 
a)
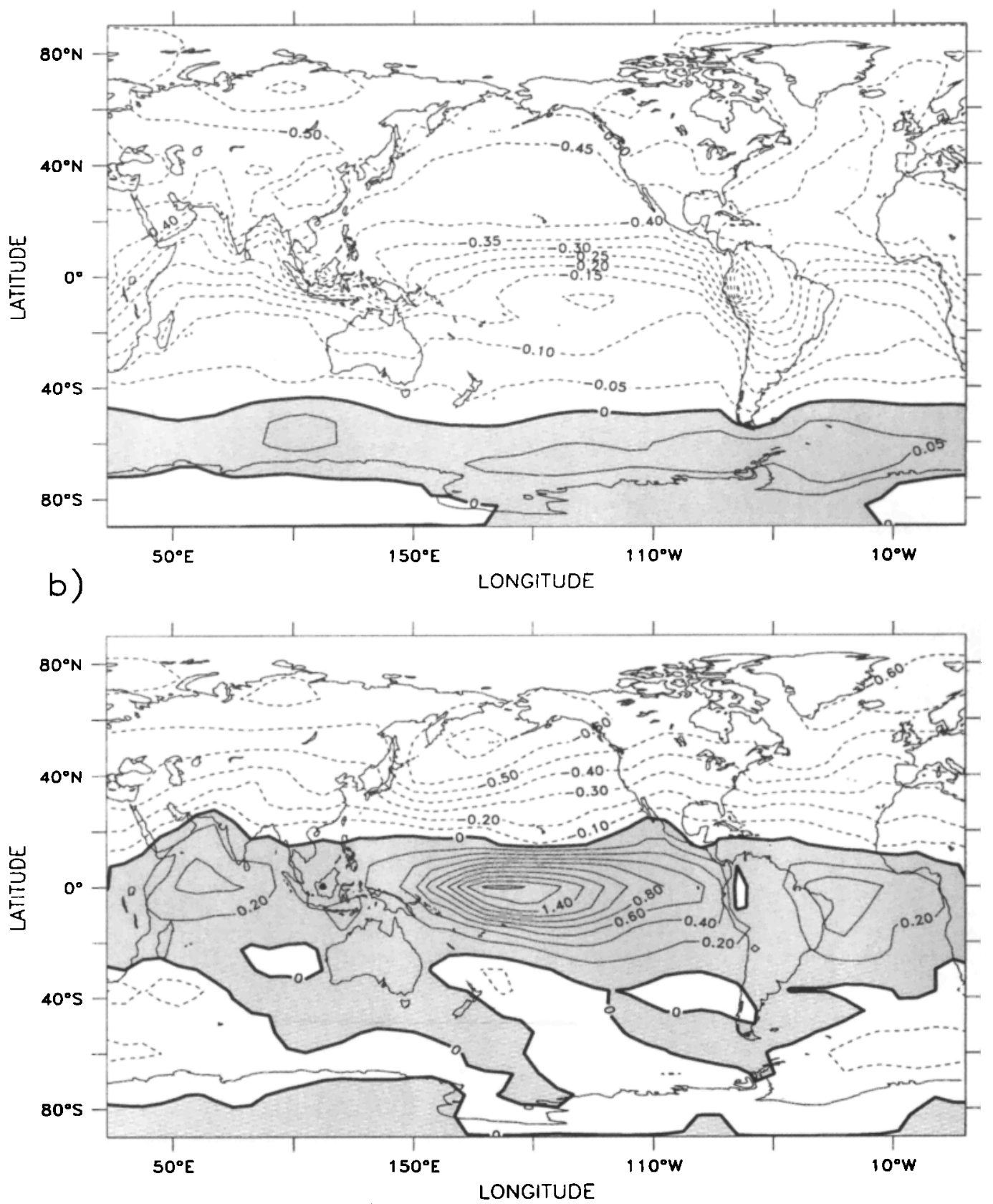

Figure 6. Annual mean distribution of atmospheric $\mathrm{CO}_{2}(\mu \mathrm{atm})$ simulated by the TM2 model when forced by (a) all components of the river carbon loop (standard run) and (b) the river carbon loop plus ocean-only fluxes (preindustrial case).

this input on atmospheric $\mathrm{CO}_{2}$ would be small. Therefore accounting for river discharge of nutrients would tend to reduce the difference between our two extreme scenarios and would not significantly increase our predicted difference in atmospheric $\mathrm{CO}_{2}$ between Mauna Loa and South Pole.

A second uncertainty is our neglect of sedimentation of partıculate organic matter. Roughly, 0.1 $\mathrm{Pg} \mathrm{C} \mathrm{yr}^{-1}$ is buried in coastal-zone sediments [Smith and Hollibaugh, 1993].
According to some estimates, only a small fraction of the coastal zone sediments may originate from the rivers [Jorgensen, 1983; Hedges and Keil, 1995]. However, the fraction of riverine organic carbon sequestered in the sediments may be underestimated in these studies because it may be recycled in the coastal zone and thus lose its riverine characteristics. An upper limit for the burial of riverine $\mathrm{POC}$ in the coastal-zone sediments would be $01 \mathrm{PgC} \mathrm{yr}^{-1}$. Addı- 
tionally, some riverine organic matter may be trapped in the deltaic systems. Although there are no global estimates for this loss, studies show that only POC is likely to be lost in river deltas [Milliman and Meade, 1983; Milliman, 1991]. Thus the maximum total loss of riverine carbon would be the total input of riverine POC, that is $0.19 \mathrm{PgC} \mathrm{yr}^{-1}(0.1$ $\mathrm{PgC} \mathrm{yr}^{-1}$ in coastal zones and $0.09 \mathrm{PgC} \mathrm{yr}^{-1}$ in the river deltas). That total represents $\sim 25 \%$ of the total river discharge of carbon. Most of the area of coastal zones is located in the Northern Hemisphere along with the land mass. Thus sedimentation of organic matter maintains the sink of atmospheric $\mathrm{CO}_{2}$ due to continental erosion, but it may reduce significantly southward carbon transport.

In summary, neither the river input of nutrients nor the sedimentation of organic matter seem to explain the discrepancy between the extrapolated difference of $-0.8 \pm 0.2$ $\mu \mathrm{atm}$ between Mauna Loa and South Pole and our model estimates. In our model, such a large difference would require a southward cross-equatorial transport of more than 1 $\mathrm{PgC} \mathrm{yr}^{-1}$. That is substantially more than the $0.3 \mathrm{PgC} \mathrm{yr}^{-1}$ estimated for the Atlantic Ocean [Keeling and Peng, 1995; Brewer et al., 1989; Holfort et al., 1998]. Therefore transport of oceanic and riverine carbon by the ocean does not explain most of the previously extrapolated preindustrial gradient between Mauna Loa and South Pole. Nevertheless, the data extrapolation assumes a linear relationship between this gradient and the fossil fuel emissions back to the preindustrial times. Such could not be the case, especially if the continental biosphere has changed over time due, for instance, to land use and $\mathrm{CO}_{2}$ fertilization.

A third uncertainty is that the river discharge of carbon used here has been estimated from empirical relations which come from river observations. Thus they may include an anthropogenic contribution. However, the GEM relations used to compute the discharge of inorganic carbon are based on lithological and drainage parameters which have not been affected by the human activities. Furthermore, the data used to calibrate the empirical relations concern only small unpolluted watersheds [Amiotte-Suchet and Probst, 1993]. For organic carbon, uncertainties concerning the anthropogenic component are larger. GEM riverine organic carbon estimates include some anthropogenic component because they are taken from rivers worldwide. However, riverine DOC data sets are mostly from areas located away from industrialized regions. Relations for riverine $\mathrm{POC}$ are based, as much as possible, on data collected before the construction of dams and reservoirs, such as the Aswan Dam on the Nile. We thus assume that the river fluxes used in this study are representative of the preindustrial situation.

Our estimates also rely on the extent to which our ocean carbon-cycle model, atmospheric tracer transport model and erosion model are realistic. Inadequacies in the simulation of the ocean's thermohaline circulation would affect carbon transport estimates. Sarmiento et al. [2000] discuss the processes controlling the preindustrial transport of carbon in their comparison of three different ocean carbon-cycle models, including the model presented here. Strong similarities in predicted interhemispheric transport of carbon by the three diverse models suggest that if substantial problems exist, they must be systematic between all three models. This possibility has been also raised by Stephens et al. [1999]. They suggest, after analyzing a limited number of atmospheric observations, that ocean carbon-cycle models may underestimate the southward transport of carbon and oxygen. They propose possible explanations for such systematic failure of ocean models, including too much convection in the Southern Ocean and too much upwelling through the thermocline in the low latitudes. However, sensitivity tests with our model (which differs from the other ocean general circulation models in that it has very little convection in the Southern Ocean and no upwelling of abyssal water in the low latitudes) show little change in atmospheric $\mathrm{CO}_{2}$ and $\mathrm{O}_{2}$ (APO) when compared to other models [Aumont, 1998]. Further comparison with ocean models and other data sets might help resolve this question. Atmospheric models also have uncertainties, particularly concerning the rectifier effect [Law et al., 1996]. However, that uncertainty does not affect our results. The rectifier effect is small for air-sea fluxes because seasonal variability is much less than for the terrestrial biosphere.

Finally, we have neglected in this study the potential effect of hydrothermal sources and volcanos on atmospheric $\mathrm{CO}_{2}$. In a sensitivity experiment mentioned previously, we have estimated the maximum impact of hydrothermal activity on the southward transport of carbon in the ocean. Its magnitude is fairly small (less than $0.03 \mathrm{PgCyr}^{-1}$ across the equator). The imbalance in $\mathrm{CO}_{2}$ fluxes due to this source is $\sim 0.05 \mathrm{Pg} \mathrm{Cyr}^{-1}$ between both hemispheres. The atmospheric model was driven by these fluxes to estimate their effect on atmospheric $\mathrm{CO}_{2}$. The predicted north-south gradient is about $-0.03 \mu \mathrm{atm}$. We have not performed a similar sensitivity experiments for volcanos. According to GEM, the maximum volcanic fluxes of $\mathrm{CO}_{2}$ is $0.09 \mathrm{Pg} \mathrm{Cyr}^{-1}$. By assuming crudely that $\sim 75 \%$ of this carbon is released in the Northern Hemisphere as the land mass distribution, the resulting north-south gradient in atmospheric $\mathrm{CO}_{2}$ should be not more than $0.04 \mu \mathrm{atm}$. Thus both processes add a rather small uncertainty of less than $\pm 0.05 \mu \mathrm{atm}$ to our estimate of the North-South gradient of atmospheric $\mathrm{CO}_{2}$. Furthermore, these processes have an antagonist impact on atmospheric $\mathrm{CO}_{2}$ and may partly compensate each other.

\subsection{Implications}

In this study, three component models have been used to estimate the regional distribution of the net fluxes of carbon between the atmosphere, land, and oceans. In this study, we have linked carbon fluxes between an erosion model, an ocean model, and an atmospheric model as a means to constrain interhemispheric transport and regional carbon budgets. Southward interhemispheric ocean transport of car- 
Table 2. Global Fluxes of Natural Carbon to the Atmosphere as Predicted in the Standard Simulation ${ }^{\text {a }}$

\begin{tabular}{lcccc}
\hline Latitude bands & Sea-air Fluxes & River Fluxes & Land Uptake & Total \\
\hline $90^{\circ} \mathrm{N}-20^{\circ} \mathrm{N}$ & -0.67 & 0.16 & -0.34 & -0.85 \\
$20^{\circ} \mathrm{N}-20^{\circ} \mathrm{S}$ & 1.40 & 0.15 & -0.31 & 1.24 \\
$20^{\circ} \mathrm{S}-90^{\circ} \mathrm{S}$ & -0.73 & 0.30 & -0.05 & -0.48 \\
\hline
\end{tabular}

${ }^{a}$ Given in $\mathrm{Pg} \mathrm{Cyr}^{-1}$. Oceanic carbon fluxes correspond to the air-sea fluxes of $\mathrm{CO}_{2}$ predicted by the ocean model without the river input of carbon. River fluxes represent loss of riverine carbon from the ocean. Land uptake corresponds to the continental uptake of carbon due to continental weathering of organic and inorganic carbon as predicted by the GEM model. The total fluxes of $\mathrm{CO}_{2}$ are not balanced (see text).

bon $\left(0.25 \pm 0.1 \mathrm{GtC} \mathrm{yr}^{-1}\right)$ is responsible for almost all of the asymmetry in air-sea fluxes fluxes between hemispheres (Table 2). Furthermore, interhemispheric transport of carbon and the north-south gradient of atmospheric $\mathrm{CO}_{2}$ do not show any clear relationship (Table 1). The latitudinal distribution of atmospheric sources and sinks is much more important in determining the north-south atmospheric $\mathrm{CO}_{2}$ gradient than is interhemispheric ocean transport. We conclude that the atmosphere cannot be treated as two well-mixed hemispheric boxes for studies of this nature.

Regional carbon budgets concerning the role of the terrestrial biosphere have relied heavily on atmospheric transport models. All such models driven by only fossil fuel emissions predict north-south gradients that exceed the observations by roughly $1.5 \mu \mathrm{atm}$ during the 1980 s [Law et al., 1996]. Accounting for the rectifier effect may even enhance this difference [Denning et al., 1995]. The misfit between the observations and the models is commonly explained by the presence of a large sink of $\mathrm{CO}_{2}$ in the land biosphere of the Northern Hemisphere midlatitudes [Tans et al., 1990; Ciais et al., 1995]. This sink has often been attributed to the anthropogenic uptake, in particular to fertilization by $\mathrm{CO}_{2}$. These studies use database estimates of the air-sea fluxes of $\mathrm{CO}_{2}$, which necessarily include the riverine component. Yet these estimates show little asymmetry between hemispheres. Unfortunately though, data is sparse and summer biased in the Southern Ocean, where most of riverine carbon is lost from the ocean to the atmosphere. More importantly, previous studies have never considered the contribution of the land erosion sink to the north-south gradient of atmospheric $\mathrm{CO}_{2}$. Here we have estimated that the land erosion sink together with the efflux of riverine carbon from the Southern Ocean may be responsible for a north-south gradient of atmospheric $\mathrm{CO}_{2}$ of up to $-0.6 \pm 0.1 \mu \mathrm{atm}$ from pole-to-pole. Thus the river loop reduces the need for a missing carbon sink in the Northern Hemisphere (Figure 7).

The location and magnitude of the missing sink remains a matter of debate. Inverse atmospheric models represent a powerful means to better constrain this sink, longitudinally as well as latitudinally [Fan et al., 1998; Rayner et al., 1999; Bousquet et al., 1999]. Such models use spatial variations in atmospheric $\mathrm{CO}_{2}$ to predict the regional distribution of the sources and sinks of $\mathrm{CO}_{2}$. Fluxes associated with the river carbon loop produce natural zonal variations of atmospheric $\mathrm{CO}_{2}$ that may exceed $0.5 \mu \mathrm{atm}$. Zonal variations of that magnitude results in predictions of large sources and sinks of carbon by inverse atmospheric models. We advocate that inverse modelers should test the sensitivity of their solutions to $a$ priori fluxes scenarios that include the river carbon loop. Accounting for the river carbon loop may especially be critical for estimating the partitioning between natural and anthropogenic carbon sinks.

\section{Conclusions}

The GEM erosion model and the IPSL global ocean carboncycle model were coupled to study the impact of the river

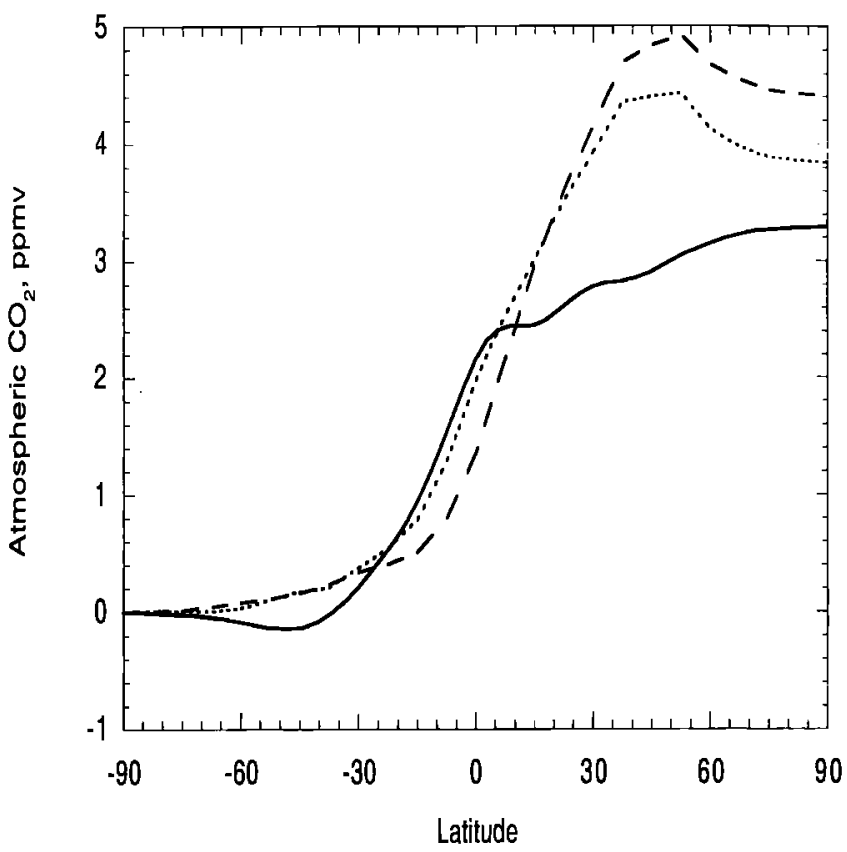

Figure 7. Zonally averaged distribution of atmospheric $\mathrm{CO}_{2}$ at the surface for the mean of observations from GLOBALVIEW for the period 1985-1995 (solid) [Masarie and Tans, 1995], the results from TM2 driven by fossil carbon emissions (dashes), and TM2 with fossil emissions and the river carbon loop (dots). 
carbon loop on the regional distribution of air-sea fluxes of $\mathrm{CO}_{2}$. Our results indicate that the river carbon loop alters estimates of preindustrial air-sea fluxes and interhemispheric transport of carbon both in the ocean and atmosphere. The delivery of riverine carbon to the ocean increases the southward transport of carbon across the equator from 0.1 to $0.35 \pm 0.1 \mathrm{PgC} \mathrm{yr}^{-1}$. This number is within the 0.3-0.6 ${\mathrm{PgC} \mathrm{yr}^{-1}}^{-1}$ range deduced from both oceanographic and atmospheric observations [Broecker and Peng, 1992; Keeling and Peng, 1995; Stephens et al., 1999]. Thus the river carbon loop appears to resolve the discrepancy between databased and model-based estimates of the ocean interhemispheric transport of carbon.

Second, we estimated the regional variations of preindustrial atmospheric $\mathrm{CO}_{2}$ by driving the atmospheric tracer transport model TM2 with flux boundary conditions from the coupled GEM-IPSL models. The river carbon loop combined with the ocean interhemispheric transport of carbon creates atmospheric $\mathrm{CO}_{2}$ concentrations at South Pole which exceed those at North Pole by $0.6 \pm 0.1 \mu \mathrm{atm}$. Furthermore, this loop induces large zonal gradients of atmospheric $\mathrm{CO}_{2}$ in the tropics reaching values up to $0.4 \mu \mathrm{atm}$ between the Andes and the central equatorial Pacific Ocean. However, the river carbon loop explains only about $1 / 4$ of the $-0.8 \pm 0.2$ $\mu \mathrm{atm}$ difference between Mauna Loa and South Pole extrapolated linearly from measured atmospheric $\mathrm{CO}_{2}$ time series at the same stations.

The north-south gradient of atmospheric $\mathrm{CO}_{2}$ created by the natural river carbon loop may explain a large portion of the difference between the observations and the gradient simulated by atmospheric models when only fossil fuel emissions are accounted for. Thus there is less need to invoke a strong anthropogenic sink in the northern terrestrial biosphere. To bring the modeled interhemispheric gradient closer to the observations and to close the carbon budget, one thus needs a reduced midlatitude and high-latitude sink of anthropogenic $\mathrm{CO}_{2}$, combined with a larger tropical anthropogenic sink, both in the terrestrial biosphere. Such regional pattern is consistent with direct measurements of the effect of $\mathrm{CO}_{2}$ fertilization on various plants [Taylor and Lloyd, 1992; Lloyd, 1999].

Acknowledgments. We thank Guy Munhoven for discussion concerning the river input of inorganic carbon and alkalinity as well as sedimentation of inorganic carbon, Jean-Claude Dutay for comments on hydrothermal activity, and Philippe Bousquet for doing most of the simulations with the atmospheric model. We also thank Peter Haugan and Michel Meybeck for discussions concerning the river carbon loop. Computational support was provided by the CEA/DSM. This work was funded by the Environment and Climate Programme of the European Community (ESCOBA-Ocean contract ENV4-CT95-0132 and ESCOBA-Biosphere contract ENVCT95-0111).

\section{References}

Amiotte-Suchet, P., and J. L. Probst, Flux de $\mathrm{CO}_{2}$ consommé par altération chimique continentale : influence du drainage et de la lithologie, C. R. Acad. Sci. Paris, 317, 615-622, 1993.
Amiotte-Suchet, P., and J. L. Probst, A global model for present day atmospheric/soil $\mathrm{CO}_{2}$ consumption by chemical erosion of continental rocks (GEM-CO 2 ), Tellus, Ser. B, 47, 273-280, 1995.

Arthur, M. A., W. E. Dean, and S. O. Schlanger, Variations in the global carbon cycle during the cretaceous related to climate, volcanism, and changes in atmospheric $\mathrm{CO}_{2}$, in The Carbon Cycle and Atmospheric $\mathrm{CO}_{2}$ : Natural Variations Archean to Present, Geophys. Monogr. Ser., edited by E. T. Sundquist and W. S. Broecker, vol. 32, pp. 504-530, AGU, Washington DC, 1985.

Aumont, O., Etude du cycle naturel du carbone dans un modèle 3D de l'océan mondial, Ph.D. thesis, Univ. Paris VI, Paris, 1998.

Aumont, O., J. C. Orr, P. Monfray, G. Madec, and E. Maier-Reimer, Nutrient trapping in the equatorial pacific: The ocean circulation solution, Global Biogeochem. Cycles, 13, 351-371, 1999.

Berner, R. A., Atmospheric carbon dioxide levels over Phanerozoic time, Science, 249, 1382-1386, 1990.

Blanke, B., and P. Delecluse, Low frequency variability of the tropical Atlantic ocean simulated by a general circulation model with mixed layer physics, J. Phys. Oceanogr., 23, 1363-1388, 1993.

Bousquet, P., P. Ciais, P. Peylin, M. Ramonet, and P. Monfray, Inverse modeling of annual atmospheric $\mathrm{CO}_{2}$ sources and sinks, 1, Method and control inversion, J. Geophys. Res., 104, 26,14126,178, 1999.

Brewer, P. G., C. Goyet, and D. Dyrssen, Carbon dioxide transport by ocean currents at $25^{\circ} \mathrm{N}$ latitude in the Atlantic Ocean, Science, 246, 477-479, 1989.

Broecker, W. S., and T. H. Peng, Gas exchange rates between air and the sea, Tellus, 26, 21-35, 1974.

Broecker, W. S., and T. H. Peng, Interhemispheric transport of carbon through the ocean, in The Global Carbon Cycle, edited by M. Heimann, pp. 551-571, Springer Verlag, New-York, 1992.

Ciais, P., et al., Partitioning of ocean and land uptake of $\mathrm{CO}_{2}$ as inferred by $\delta^{13} \mathrm{C}$ measurements from the NOAA Climate Monitoring and Diagnostics Laboratory Global Air Sampling, J. Geophys. Res., 100, 5051-5070, 1995.

Delecluse, P., M. Imbard, C. Lévy, and G. Madec, OPA-Ocean General Circulation model, reference manual, Lab. Océ. Dyn. Clim., Univ. Paris VI, Paris, 1993.

Denning, A. S., I. Y. Fung, and D. Randall, Latitudinal gradient of atmospheric $\mathrm{CO}_{2}$ due to seasonal exchange with land biota, Nature, 376, 240-243, 1995.

Des Marais, D. J., Carbon exchange between the mantle and the crust, and its effect upon the atmosphere: Today compared to Archean time, in The Carbon Cycle and Atmospheric $\mathrm{CO}_{2}$ : Natural Variations Archean to Present, Geophys. Monogr. Ser., edited by E. T. Sundquist and W. S. Broecker, vol. 32, pp. 602611, AGU, Washington DC, 1985.

Fan, S., M. Gloor, J. Mahlman, S. Pacala, J. Sarmiento, T. Takahashi, and P. Tans, A large terrestrial carbon sink in North America implied by atmospheric and oceanic carbon dioxide data and models, Science, 282, 442-446, 1998.

Frankignoulle, M., G. Abril, A. Borges, I. Bourge, C. Canon, B. Delille, E. Libert, and J. M. Théate, Carbon dioxide emission from European estuaries, Science, 282, 434-436, 1998.

Gaspar, P., Y. Gregoris, and J. M. Lefevre, A simple eddy kinetic energy model for simulations of the ocean vertical mixing: Tests at station Papa and Long-Term Upper Ocean Study Site site, $J$. Geophys. Res., 95, 16,179-16,193, 1990.

Hedges, J. I., and R. G. Keil, Sedimentary organic matter preservation: an assessment and speculative synthesis, Mar. Chem., 49, 81-115, 1995.

Heimann, M., The global atmospheric tracer model tm2, Tech. Rep. 10, Deutsches Klimarechenzentrum, Hamburg, Germany, 1995.

Heimann, M., and C. D. Keeling, A three-dimensional model of atmospheric $\mathrm{CO}_{2}$ transport based on observed winds: 2.Model description and simulated tracer experiments, in Aspects of Cli- 
mate Variability in the Pacific and Western Americas, Geophys. Monogr. Ser, edited by D. H. Peterson, vol. 55, pp. 237-275, AGU, Washington D.C., 1989.

Heimann, M., C. D. Keeling, and I. Y. Fung, Simulating the atmospheric carbon dioxide distribution with a three-dimensional tracer model, in The Changing Carbon Cycle: A Global Analysis, edited by J. R. Trabalka and D. E. Reichle, pp. 16-49, Springer-Verlag, New York, 1986.

Hellermann, S., and M. Rosenstein, Normal monthly windstress over the world ocean with error estimates, J. Phys. Oceanogr. 24, 619-637, 1983.

Holfort, J., K. M. Johnson, B. Schneider, G. Siedler, and D. W. R. Wallace, Meridional transport of dissolved inorganic carbon in the South Atlantic Ocean, Global Biogeochem. Cycles, 12, 479500, 1998.

Jorgensen, B. B., Processes at sediment-water interface, in The Major Biogeochemical Cycles and Their Interactions, edited by B. Bolin and R. B. Cook, vol. 21, pp. 477-509, John Wiley, New York, 1983.

Keeling, C. D., R. B. Bacastow, A. F. Carter, S. C. Piper, T. P. Whorf, M. Heimann, W. G. Mook, and H. Roeloffzen, A Three dimensional model of atmospheric $\mathrm{CO}_{2}$ transport based on observed winds, 1, Analysis of observational data, in Aspects of climate Variability in the Pacific and Western Americas, Geophys. Monogr. Ser., edited by D. H. Peterson, vol. 55, pp. 165-236, AGU, Washington DC, 1989.

Keeling, R. F., and T. H. Peng, Transport of heat, $\mathrm{CO}_{2}$, and $\mathrm{O}_{2}$ by the Atlantic's thermohaline circulation, Philos. Trans. R. Soc. London, Ser. B, 348, 133-142, 1995.

Law, R. M., et al., Variations in modelled atmospheric transport of carbon dioxide and the consequences for $\mathrm{CO}_{2}$ inversions, Global Biogeochem. Cycles, 10, 783-796, 1996.

Lloyd, J., Current perspectives on the terrestrial carbon cycle, Tellus, Ser. B, 51, 336-342, 1999.

Ludwig, W., and J. L. Probst, River sediment discharge to the oceans: Present day controls and global budgets, Am. J. of Sci., 298, 265-295, 1998.

Ludwig, W., P. Amiotle-Suchet, and J. L. Probst, River discharge of carbon to the world's oceans: Determining local inputs of alkalinity and of dissolved and particulate organic carbon, $C . R$. Acad. Sci. Paris, 323, 1007-1014, 1996a.

Ludwig, W., J. L. Probst, and S. Kempe, Predicting the oceanic input of organic carbon by continental erosion, Global Biogeochem. Cycles, 10, 23-41, 1996b.

Madec, G., and M. Imbard, A global ocean mesh to overcome the North Pole singularity, Clim. Dyn., 12, 381-388, 1996.

Maier-Reimer, E., Geochemical cycles in an ocean general circulation model: Preindustrial tracer distributions, Global Biogeochem. Cycles, 7, 645-677, 1993.

Masarie, K. A., and P. P. Tans, Extension and integration of atmospheric carbon dioxide data into a globally consistent measurement record, J. Geophys. Res., 100, 11,593-11,610, 1995.

Meybeck, M., Riverine transport of atmospheric carbon: Sources, global typology and budget, Water, Air, Soil Pollut., 70, 443-463, 1993a.

Meybeck, M., N, P and S in rivers: From sources to global inputs, in Interactions of $C, N, P$, and $S$ Biogeochemical Cycles and Global Change, NATO ASI Ser., edited by R. Wollast, F. T. Mackenzie, and L. Chou, vol. I 4, pp. 163-197, Springer-Verlag, New York, i993b.

Miller, J. R., G. L. Russell, and G. Caliri, Continental-scale river flow in climate models, J. Climate, 7, 914-928, 1994.

Milliman, J. D., Flux and fate of fluvial sediment and water in coastal seas, in Ocean Margin Processes in Global Change, edited by R. F. C. Mantoura, J. M. Martin, and R. Wollast, pp. 69-89, Wiley-Interscience, New York, 1991.

Milliman, J. D., and R. H. Meade, World-wide delivery of river sediments to the oceans, J. Geol., 91, 1-21, 1983.

Oberhüber, J. M., An atlas on the 'COADS' Data Set: The Budget of Heat, Buoyancy, and Turbulent Kinetic Energy at the Surface of the Global Ocean, chap. 15, Max-Planck Inst. für Meteorol., Hamburg, Germany, 1988.

Orr, J. C., Ocean Carbon-Cycle Model Intercomparison Project (OCMIP): Phase 1 (1995-1997), GAIM Rep. 7, IGBP/GAIM Office, Univ. New Hampshire, Durham, 1999.

Pearman, G. I., and P. Hyson, Activities of the global biosphere as reflected in atmospheric $\mathrm{CO}_{2}$ records, J. Geophys. Res., 85, 4468-4474, 1980.

Ramonet, M., Modélisation du transport atmosphérique du dioxyde de carbone dans l'hémisphère sud, Ph.D. thesis, Univ. Paris VII, Paris, 1994.

Rayner, P., I. Enting, R. Francey, and R. Langenfelds, Reconstructing the recent carbon cycle from atmospheric $\mathrm{CO}_{2}, \delta^{13} \mathrm{c}$ and $\mathrm{O}_{2} / \mathrm{N}_{2}$ observations, Tellus, Ser. B, 51, 213-232, 1999.

Sarmiento, J. L., and E. T. Sundquist, Revised budget for the oceanic uptake of anthropogenic carbon dioxide, Nature, 356, 598-593, 1992.

Sarmiento, J. L., P. Monfray, E. Maier-Reimer, O. Aumont, R. Murnane, and J. C. Orr, Spatial distribution of oceanic $\mathrm{CO}_{2}$ sources and sinks: A comparison of three ocean general circulation models, Global Biogeochem. Cycles, 14, 1267-1282, 2000.

Siegenthaler, U., and J. L. Sarmiento, Atmospheric carbon dioxide and the ocean, Nature, 365, 119-125, 1993.

Smith, S. V., and J. T. Hollibaugh, Coastal Metabolism and the oceanic organic carbon balance, Rev. of Geophys., 31, 75-89, 1993.

Stephens, B. B., R. F. Keeling, M. Heimann, K. D. Six, R. Murnane, and $\mathrm{K}$. Caldeira, Testing global ocean carbon cycle models using measurements of atmospheric $\mathrm{O}_{2}$ and $\mathrm{CO}_{2}$ concentration, Global Biogeochem. Cycles, 12, 213-230, 1999.

Takahashi, T., W. S. Broecker, and S. Langer, Redfield ratio based on chemical data from isopycnal surfaces, J. Geophys. Res., 90, 6907-6924, 1985.

Tans, P. P., I. Y. Fung, and T. Takahashi, Observational constraints on the global atmospheric $\mathrm{CO}_{2}$ budget, Science, 247, 14311438, 1990.

Taylor, J. A., and J. Lloyd, Sources and sinks of atmospheric $\mathrm{CO}_{2}$, Aust. J. Bot., 40, 407-418, 1992.

Taylor, J. A., and J. C. Orr, The natural latitudinal distribution of atmospheric $\mathrm{CO}_{2}$, Global and Planetary Change, 2000, in press.

P. Amiotte-Suchet, Laboratoire GéoSol, Université de Bourgogne, 6 boulevard Gabriel, 21000 Dijon, France. (phamiots@ubourgogne.fr)

O. Aumont, J. C. Orr, and P. Monfray, Laboratoire des Sciences du Climat et de l'Environnement, DSM, CE Saclay, CEA, L'Orme des Merisiers, Bâtiment 709, F-91191 Gif sur Yvette, Cedex, France. (aumont@lsce.saclay.cea.fr; or @lsce.saclay.cea.fr; monfray@lsce.saclay.cea.fr)

W. Ludwig, Centre de Formation et de Recherche sur l'Environnement Marin, Université de Perpignan, 52 avenue de Villeneuve, F-66860 Perpignan, France. (ludwig@univ-perp.fr)

J. L. Probst, Laboratoires des mécanismes de Transferts en Géologie, Université Paul Sabatier, 38 rue des 36 ponts, 31400 Toulouse, France. (jlprobst@illite.u-strasbg.fr)

(Received October 19, 1999; revised May 31, 2000; accepted July 15, 2000.) 